\title{
Study on Microstructure and Properties of Aeronautical Nickel-Based Superalloy in Laser Directional Solidification
}

\author{
Aiyong CUI *, Huakai WEI, Haodong LIU, Bin HU, Hui YU \\ Naval Aeronautical University, Qingdao Campus, Qingdao, Shandong, China, 266041 \\ crossref http://dx.doi.org/10.5755/j02.ms.23522
}

Received 04 June 2019; accepted 16 September 2019

\begin{abstract}
For the directional solidification repair of blade damage in an aviation turbine, a directional-growth repair layer on the surface of a nickel-based superalloy was prepared using an Nd:YAG laser. The microstructure of the directional-growth repair layer was investigated using scanning electron microscopy and transmission electron microscopy. Its phase composition and corrosion resistance were also analyzed and tested. The results indicate that the grains in the repair zone solidified in the same direction as the substrate and formed continuous columnar crystals, which were arranged in an orderly manner. A small number of secondary dendritic cells were dispersed in the transverse direction of the columnar crystals. The phase composition was mainly composed of the $\alpha^{\prime}$-based phase, $\beta$-precipitated strengthening phase, MC carbide, and interdendritic $\alpha^{\prime} / \beta$ eutectic phase. The corrosion kinetic curve of the repair zone changed linearly. The oxide film was uniform and dense, and was mainly composed of continuous granular oxide. The corrosion kinetic curve of the substrate conformed to the parabolic law. The oxide film was composed of loose and bulky granular grains, which were stacked in the shape of regular polyhedra and distributed in the form of an island.

Keywords: laser directional solidification, nickel-based superalloy, microstructure, formation phase, corrosion resistance.
\end{abstract}

\section{INTRODUCTION}

The turbine blade is considered to be the most important component of an aero-engine because it has to withstand the most complex loads and harshest application conditions, and hence it can even be called the "Pearl on the Crown". Its performance has become an important indicator of the level of sophistication of the engine, and in a certain sense, it is also a significant indicator of the technological advancement of the aviation industry [1]. Directional solidification technology is a major advancement in the turbine blade casting process. This technology facilitates the directional arrangement of grains along the direction of the heat flow loss, which substantially eliminates the weak transverse grain boundaries perpendicular to the stress axis. Therefore, it has high temperature strength, good creep resistance and endurance properties, high thermal fatigue resistance, large plasticity, and good vibration damping effect. However, it is expensive due to its pearl-like status [2,3]. Thus, the repair and secondary utilization of damaged blades have become hot topics in industry-oriented research.

For the repair of turbine blade damage by directional solidification, it is necessary to ensure that the crystallization direction of the new casting part is consistent with the original direction; that is, not only the "broken limb" but also the "blood vessel" connection must be ensured. Otherwise, even if the repaired zone appears to be integrated with the original blade, it will fail by peeling off from the substrate under the action of high temperature and heavy loads. Directional solidification casting produces coarse crystal grains, severe segregation of alloying elements, and high content of precipitation-strengthening alloying elements ( $\mathrm{Al}, \mathrm{Ti}$, etc.). Such components are difficult to repair by traditional techniques, and the heat input required is large. The heat-affected zone is prone to hot cracks. In addition, the high heat input causes the blade to re-melt and recrystallize locally, destroying its directional characteristics and affecting the service life $[4,5]$. However, laser cladding technology has the advantages of local heating, low heat input, and ultra-high temperature gradient $[6,7]$. It is of great engineering significance to explore the directional growth and repair techniques of turbine blades. So, the microstructure, phase composition and corrosion resistance of laser directional-growth repair on the surface of DZ22 were investigated here.

Table 1. Chemical composition of DZ22 (wt.\%)

\begin{tabular}{|c|c|c|c|c|c|c|c|c|c|c|c|c|}
\hline $\mathrm{C}$ & $\mathrm{Mn}$ & $\mathrm{Si}$ & $\mathrm{S}$ & $\mathrm{P}$ & $\mathrm{Ni}$ & $\mathrm{Cr}$ & $\mathrm{Al}$ & $\mathrm{Ti}$ & $\mathrm{Hf}$ & $\mathrm{Co}$ & $\mathrm{W}$ & $\mathrm{Nb}$ \\
\hline 0.15 & 0.15 & 0.1 & 0.01 & 0.008 & $\mathrm{Bal}$ & 8.8 & 5.0 & 2.1 & 1.6 & 9.5 & 11.8 & 1.0 \\
\hline
\end{tabular}

Table 2. Chemical composition of the homemade alloy powder (wt.\%)

\begin{tabular}{|c|c|c|c|c|c|c|c|c|}
\hline $\mathrm{Cr}$ & $\mathrm{Co}$ & $\mathrm{W}$ & $\mathrm{Ti}$ & $\mathrm{Mo}$ & $\mathrm{Al}$ & $\mathrm{Fe}$ & $\mathrm{C}$ & $\mathrm{Ni}$ \\
\hline 18 & 15 & 1.5 & 5 & 3 & 2.5 & 0.5 & 0.1 & $\mathrm{Bal}$. \\
\hline
\end{tabular}

\footnotetext{
${ }^{*}$ Corresponding author. Tel.: 13285326895.

E-mail address: caylaser@163.com (A. Cui)
} 


\section{METHODS}

\subsection{Experimental materials}

The experimental material used was the aeronautical DZ22 substrate with a thickness of $5 \mathrm{~mm}$, which was purchased and annealed from Vestern Titanium Technologies co., LTD. The chemical composition is shown in Table 1. The chemical composition of the homemade alloy powder is shown in Table 2. The powder has a purity of $99.9 \%$ and a particle diameter of $20 \mu \mathrm{m} \sim 40 \mu \mathrm{m}$ and was fully mechanically mixed after grinding and prepared by the coaxial powder feeding method.

\subsection{Experimental procedure}

A JHM-1GX-200B pulsed Nd:YAG laser was used for the experiment, and the Japanese ERCR-HP3-AA00 robot was used as the actuator. The process parameters are: single pulse energy of $15 \mathrm{~J} \sim 30 \mathrm{~J}$, scanning speed of $3 \mathrm{~mm} / \mathrm{s} \sim 6 \mathrm{~mm} / \mathrm{s}$, pulse width of $8 \mathrm{~ms} \sim 15 \mathrm{~ms}$, frequency of $6 \mathrm{~Hz} \sim 12 \mathrm{~Hz}$, and light spot diameter of $2.5 \mathrm{~mm}$. The process was protected using high purity argon. The overlapping ratio of multi-pass layers is $30 \%$. Hot corrosion test was performed using the mixed salt of $\mathrm{Na}_{2} \mathrm{SO}_{4}(75 \mathrm{wt} . \%)+\mathrm{NaCl}(25 \mathrm{wt} . \%)$ at room temperature $\left(25^{\circ} \mathrm{C}\right)$ and high temperature $\left(800^{\circ} \mathrm{C}\right)$ in a box furnace for $20 \mathrm{~h} \sim 100 \mathrm{~h}$. The specific process is as follows: every $20 \mathrm{~h}$, remove from the furnace, cool in the air, clean the remaining salt on the surface by deionized water, dry and weigh, repeat the above process, take the average value of 5 samples as the final data. The corrosion product was protected by Ni plating on the surface.

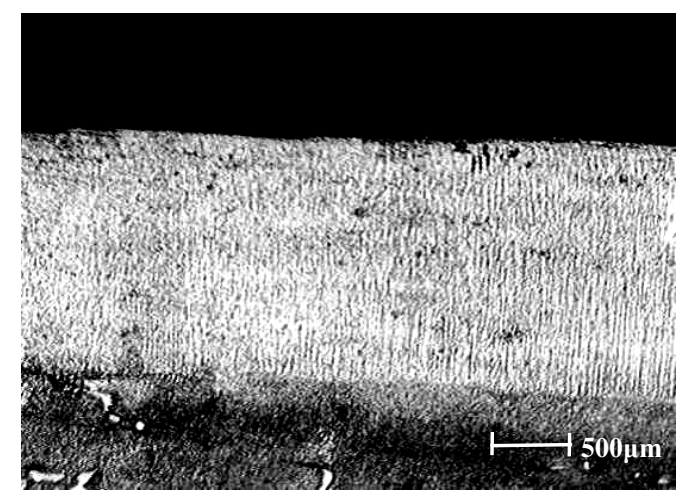

a

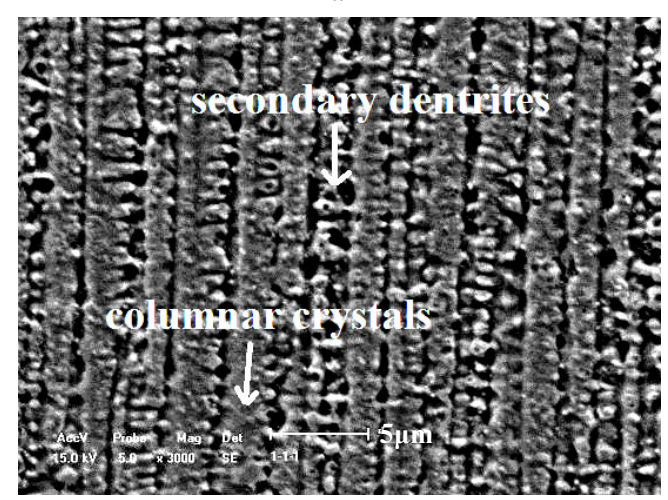

C

\subsection{Performance testing}

The morphological and structural characterizations were performed using a Toyota Hitachi S-3500N scanning electron microscopy (SEM) and TECNAI G2 20 Transmission Electron Microscope (TEM, accelerating voltage $200 \mathrm{kV}$, current $20 \mathrm{~mA} \sim 30 \mathrm{~mA}$, voltage $50 \mathrm{~V} \sim 60 \mathrm{~V}$, temperature $-20^{\circ} \mathrm{C} \sim 30^{\circ} \mathrm{C}$ ). The chemical composition of the samples was studied by energy dispersive spectroscopy (EDS, INCA, Oxford, UK). The evolution of corrosion was measured by the TG-328A photoelectric analytical balance.

\section{RESULTS AND DISCUSSION}

\subsection{Morphology analysis}

Fig. 1 a shows the SEM images of the sample in the repair zone (scanning speed $5 \mathrm{~mm} / \mathrm{s}$, pulse laser current $120 \mathrm{~A}$, pulse width $9 \mathrm{~ms}$, frequency $10 \mathrm{~Hz}$ ). It can be seen that the directional grain growth with columnar crystals at the bottom is strong and in a direction perpendicular to the junction zone. The growth directions are parallel to each other and consistent with those of the substrate grains. The columnar crystal is slender and has a transverse width of about $2 \mu \mathrm{m}$, with practically no secondary dendrite arms as shown in Fig. 1 b. The grains in the middle of the repair zone continue to grow on the grains at the bottom in the same direction and form continuous columnar crystals. A small amount of secondary dendritic cells is dispersed in the transverse direction of the columnar crystals.

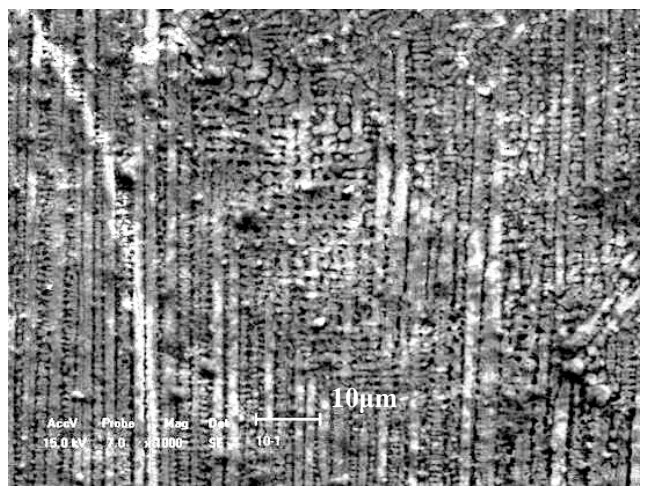

b

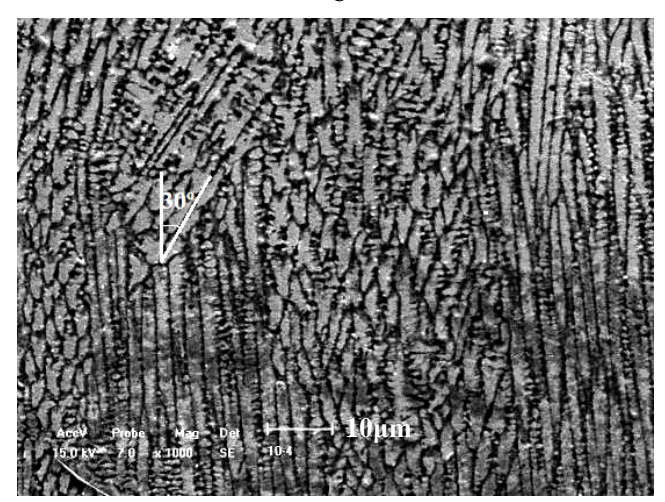

d

Fig. 1. SEM images of the sample in the repair zone: $a$-macrostructure of the repair zone; b-bottom of the repair zone; $c$-middle of the repair zone; $d$ - upper part of the repair zone 
The growth of secondary dendrites, which are perpendicular to the surface of the substrate, is significantly inhibited owing to the heat flow direction in the middle of the repair zone during the laser cladding process. The heat flows from the bottom up. The temperature difference exceeds $10^{3}$ degrees. The dendrites grow preferentially along the direction of the temperature gradient and the transverse growth of the dendrites is inhibited [8-10]. The transverse width of the columnar crystal is large $(2 \mu \mathrm{m} \sim 4 \mu \mathrm{m})$ as shown in Fig. 1 c. The vertical growth of the columnar crystals in the upper part of the repair zone is suppressed, and the longitudinal dimension is small. The growth direction of the columnar crystals deviates from the preferred orientation of the substrate grains by a certain angle $\left(0^{\circ} \sim 30^{\circ}\right)$ as shown in Fig. 1 d. In addition, the figure shows some small equiaxed crystals that coexist. The temperature at the top of the molten pool is reduced and the speed of solidification is increased. The solute accumulation component in the liquid phase is increased due to supercooling and the number of nucleation sites also increase. The grains can grow freely in all directions in the molten pool. However, the solidification speed is too large, and the dendrites cannot continue to grow in time, eventually leading to the formation of fine equiaxed crystals. In short, the repair zone is tightly integrated with the substrate. The grains in the repair zone solidified and grew in the same direction as those of the substrate, which penetrates the whole of the repair zone and achieves the desired directional solidification structure. This is consistent with the "ribbon tissue" discovered by Boettinger [11] and the "component overcooling theory to explain the formation of ribbon tissue during solidification." At the same time, it is proved that it is possible to obtain a relatively ideal directional solidification structure by controlling the crystal parameters. according to the theory of "the direction of growth of the branching axis can determine the direction of the directional crystal axis" by D. Walton's [12].

The microstructures of the sample are examined using transmission electron microscopy, as shown in Fig. 2. The dislocations are obvious in the zone of disorderly grain growth, indicating that the residual stress and tendency of cracking are large. The grain arrangement in the directional solidification zone is relatively regular.

Fig. 3 gives the morphology of the formation phase in the repair zone. It can be seen that the repair zone is mainly composed of the $\alpha^{\prime}$-based phase, $\beta$-precipitated strengthening phase in the later stages of solidification, MC carbide, and interdendritic $\alpha^{\prime} / \beta$ eutectic phase in the final stage of solidification. In 1994, Lee and Verhoeven [13] discovered symbiotic tissue in the directional solidification of Ni-Al alloys first. Yongchang Liu and Meng Wang [15] obtained two-phase lamellar tissue in directional crystallization experiments too. The long strip of MC carbide generally appears at the bottom of the repair zone, which has an adverse effect on performance. Clearly, there are two different sizes of the $\beta$ phase.

\subsection{The formation phase}

Fig. 3 gives the morphology of the formation phase in the repair zone.

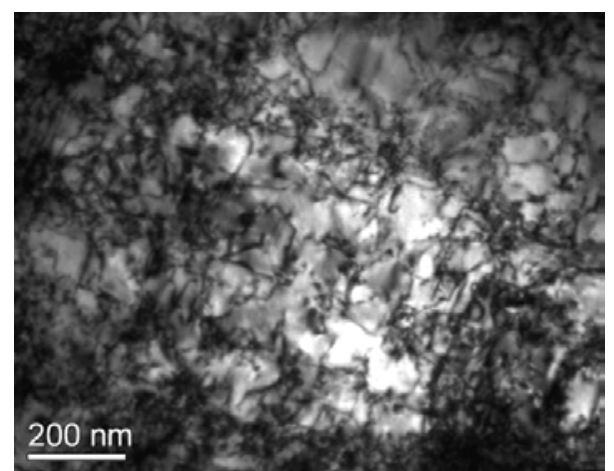

a

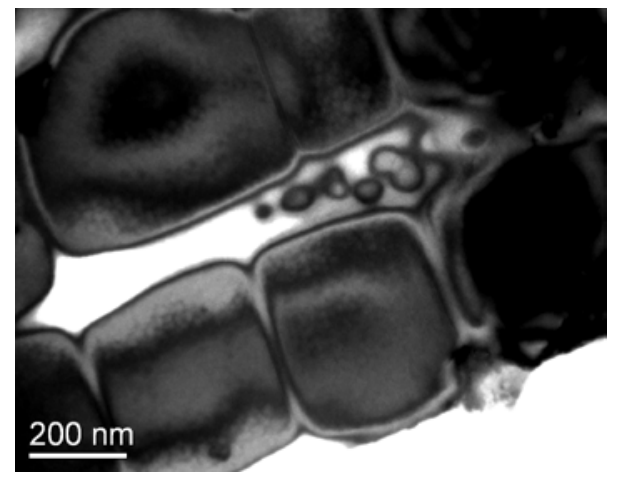

b

Fig. 2 TEM morphologies of the sample: a-grain growth disorder zone; $b$-directional solidification zone

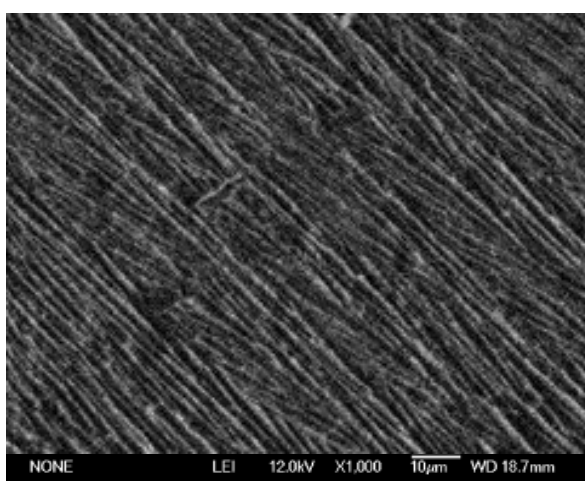

a

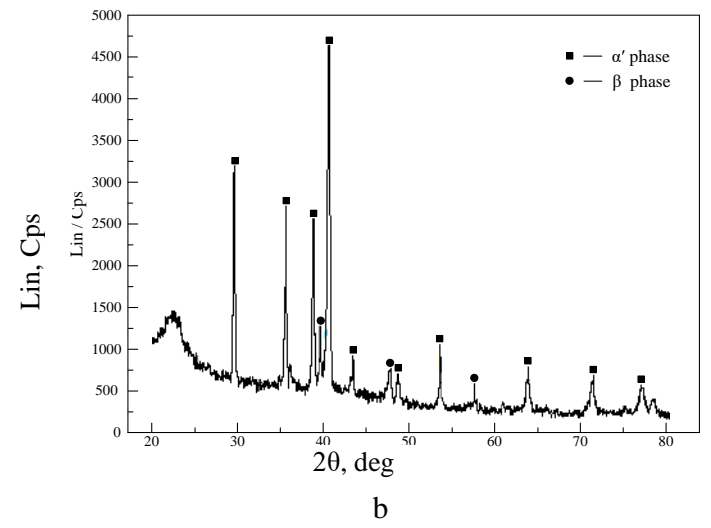

Fig. 3. Microstructure and XRD patterns of the formation phase in the repair zone: $\mathrm{a}$-morphology; $\mathrm{b}-\mathrm{XRD}$ patterns

The small-sized round granular $\beta$ phase has a size of about $20 \mathrm{~nm}$, and the large-sized block-shaped $\beta$ phase has a size of about $1 \mu \mathrm{m} \sim 2 \mu \mathrm{m}$. The small-sized $\beta$ phase generally exists in the dendrites, and the large-sized $\beta$ 
phase generally exists between the dendrites. Because the components content ( $\mathrm{Al}, \mathrm{Ti}$, etc.) forming the interdendritic $\beta$ phase are more than the elements in the dendrites, the interdendritic supersaturation is greater than that of the dendrite arm. The nucleation rate of the interdendritic $\beta$ phase is suitable for the promotion of growth. Therefore, the size of the interdendritic $\beta$ phase is large.

Fig. 4 shows the comparison of the thermal corrosion kinetics of the repaired material and the substrate.

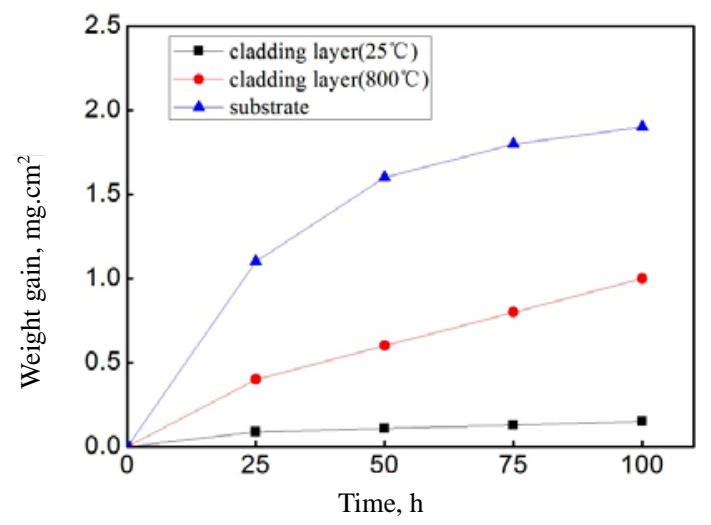

Fig. 4. Comparison of thermal corrosion kinetics of substrate and repaired material

It can be seen that the repaired material contains less corrosion products at room temperature. The corrosion is not obvious and the corrosion resistance is strong at room temperature. When the temperature rises to $800^{\circ} \mathrm{C}$, the presence of corrosion products in the substrate and repaired material increase significantly, and the increase in the substrate is greater than that in the repaired material, indicating that the corrosion resistance of the repaired material is higher than that of the substrate at high temperature. The weight of the repaired material changes linearly roughly after $25 \mathrm{~h}$, and the change rate of the substrate decreases continuously. The corrosion kinetic curves basically conform to the parabolic variation, which is due to the spalling of corrosion products during the corrosion process, the same as Wenfang Cui's conclusion on the thermal corrosion of Ti-1100 high-temperature titanium alloy [16].

\subsection{Thermal corrosion resistance test}

Fig. 5 and Fig. 6 shows the corroded surface morphologies of the repaired material at room temperature. Obviously, when the material corrosion is measured after $25 \mathrm{~h}$, it can be seen that corrosion pits begin to appear and the surface is no longer flat. At $50 \mathrm{~h}$, the quantity of corrosion products increase. The corrosion products are mainly oxides $\left(\mathrm{Cr}_{2} \mathrm{O}_{3}, \mathrm{Ni}_{2} \mathrm{O}_{3}\right)$ and carbides. When the material corrosion is measured at $75 \mathrm{~h}$, the corrosion pits become larger and increase in number, and finally by $100 \mathrm{~h}$, holes are formed due to corrosion.

Fig. 7 shows the corrosion surface morphologies of the repaired material and substrate at high temperatures. It can be seen that the corrosion at high temperatures is significantly worse than that at room temperature, and the quantity of surface corrosion products increase significantly.

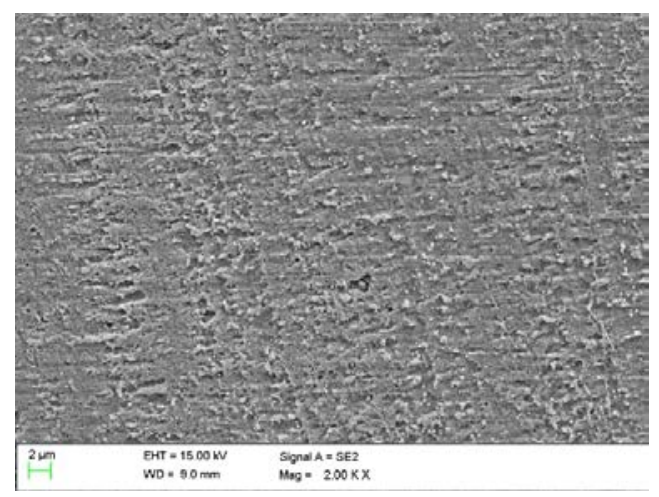

$\mathrm{a}$

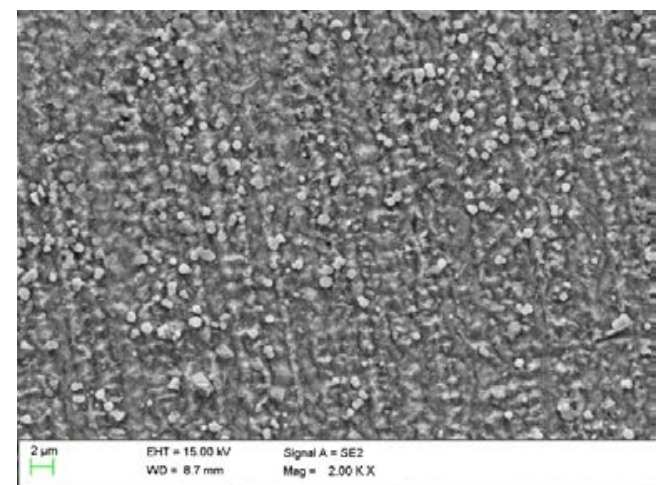

$\mathrm{b}$

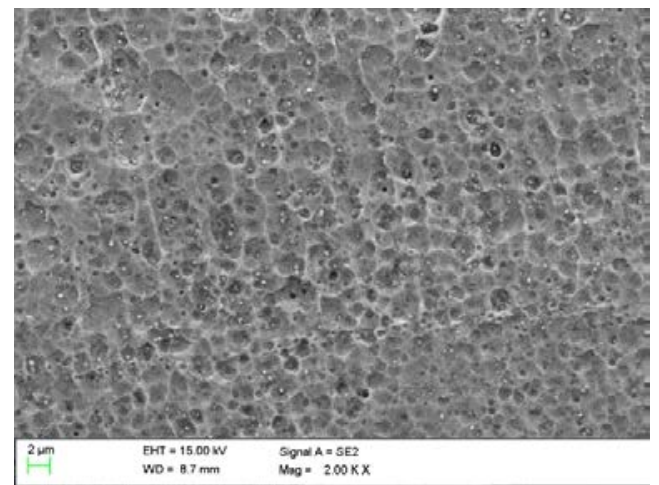

$\mathrm{C}$

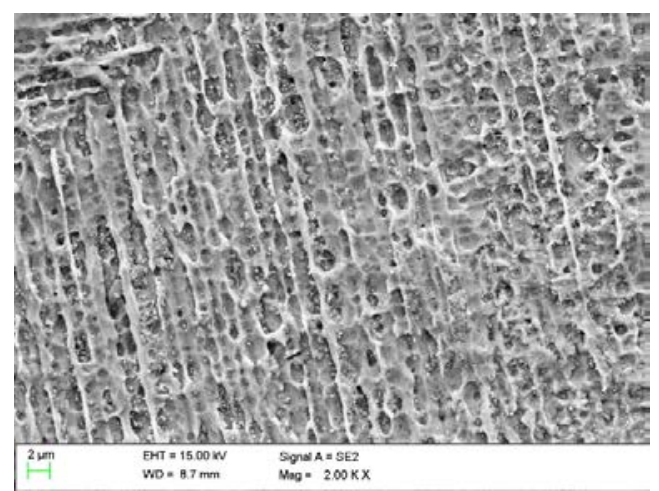

d

Fig. 5. The SEM photos of room-temperature corrosion surface: a - 25 h; b-50 h; c-75 h; d-100 h (e) EDX spectrum

The oxide film formed on the surface of the repaired material is uniform and dense and is mainly composed of continuous granular oxides. However, the oxide is formed largely during the corrosion incubation period due to the large oxidation rate of the substrate. 


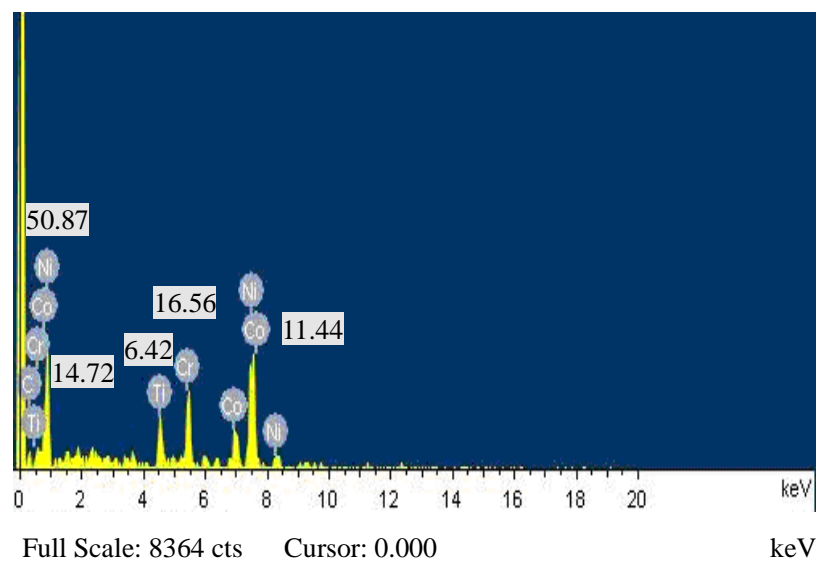

Fig. 6. EDX spectrum

It forms the inner compact layer and then diffuses outward. This change causes the outer oxide film to be composed mainly of loose granular grains, which are stacked in a regular polyhedral shape and distributed in the manner of an island. The crystal grains are coarse as shown in Fig. 7 c. During the cooling process, the difference between the thermal expansion coefficient of the oxide film and the substrate along with the brittleness of the oxide film cause the oxide film to peel off severely and lose the oxidation resistance when it reaches a certain thickness. Since the oxide layer is not dense, it is easy for the ambient oxygen to pass through the outer oxide layer to accelerate the oxidation reaction between the oxygen and the substrate.

After the oxide skin on the surface peels off, the surface of the substrate appears as an inner compact layer. The re-grown oxide is finer and denser, as shown in Fig. 6 d. Kaifeng Qi [17] and Minqing Wang [18] also found similar phenomena in the study of high temperature oxidation behavior of $\mathrm{Ti}(\mathrm{C} . \mathrm{N})$ base ceramics and GH4720Li alloys.

\section{CONCLUSIONS}

1. The repair zone is closely combined with the substrate. The crystal grains and the substrate are solidified in the same direction. They form continuous columnar crystals and are arranged in an orderly manner. They penetrate the entire repair zone to achieve an ideal directional solidification structure.

2. The phase composition is dominated by the $\alpha^{\prime}$-based phase, $\beta$-precipitated strengthening phase, MC carbide, and dendritic $\alpha^{\prime} / \beta$ eutectic phase.

3. The corrosion kinetic curve of the repair zone changes linearly. The oxide film is uniform and dense and is mainly composed of continuous granular oxides. The corrosion kinetic curve of the substrate follows the parabolic law. The oxide film is composed of loose coarse grains, which are stacked in the shape of regular polyhedra and distributed the form of an island.

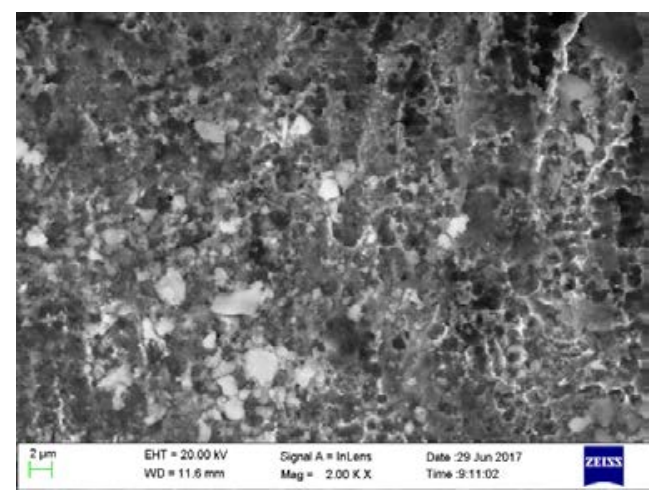

a

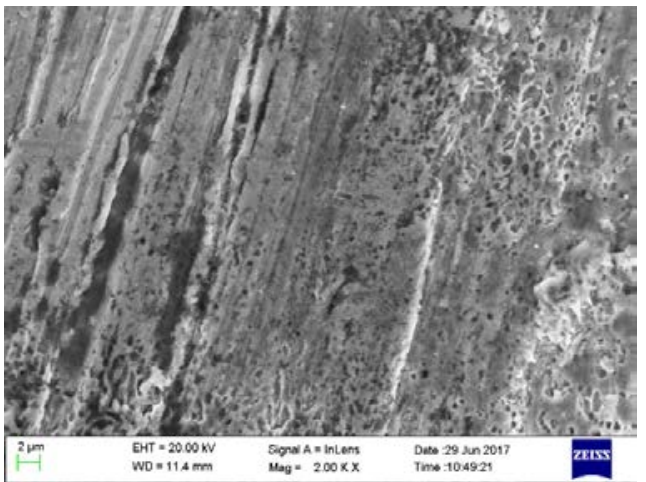

b

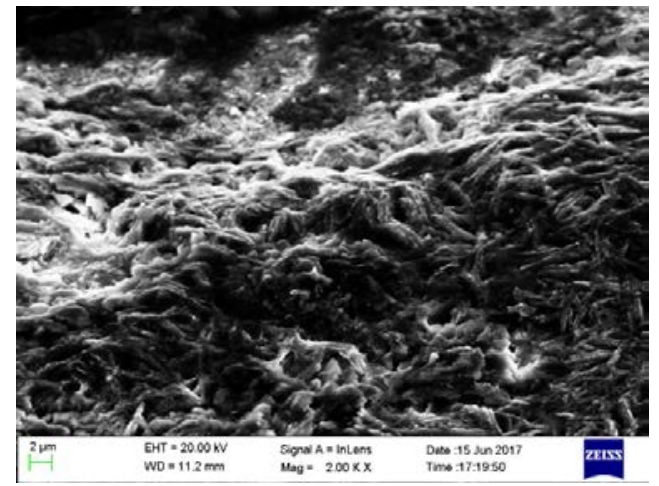

C

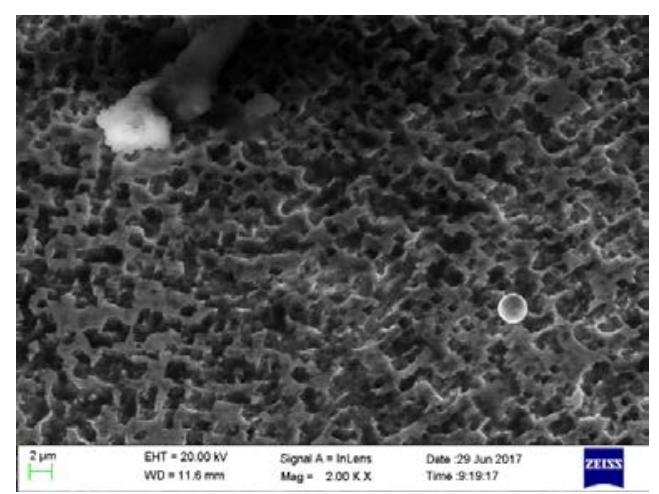

d

Fig. 7. The SEM photos of high-temperature corrosion surface: a - repaired material (75 h); b-repaired material (100 h); c-substrate (75 h); d-substrate (100 h) 


\section{REFERENCES}

1. Fu, Q.Q., Tong, Y.P., Yang, Y.Z. Failure Analysis of Thermal Barrier Coatings Deposited on Turbine Blades Failure Analysis and Prevention 12 (6) 2017: pp. 376-380. https://doi.org/10.3969/j.issn.1673-6214.2017.06.009

2. Ma, D.X. Development of Single Crystal Solidification Technology for Production of Superalloy Turbine Blades Acta Metallurgica Sinica $51(10)$ 2015: pp. 1179-1190. https://doi.org/10.11900/0412.1961.2015.00380

3. Jiang, R.S., Wang, W.H., Wang, Z.Q., Zhang, D.H., Bian, K. Precision Forming Technology and Its Development Trend of Aeroengine Turbine Blade Blade Manufacturing Technology 21 2016: pp. 57-60. https://doi.org/10.16080/j.issn.1671-833x.2016.21.057

4. Yang, S., Yu, J.J. Development and Application of Single Crystal Engine Turbine Blade Mechanical Science and Technology for Aerospace Engineering 36 (Sl.) 2017: pp. 115-122.

5. Liu, E.Z., Zheng, Z., Tong, J., Ning, L.K. Study of A Novel DS Superalloy DZ142 Rare Metal Materials and Engineering 40 (7) 2011: pp. 1129-1132. https://doi.org/ 10.1016/S1875-5372(11)60043-X

6. Tao, Y.Y., Xue, W.P., Tang, H.F., Su, Y.L., Huang, S.Z., Zhao, X.M. Application of Laser Additive Manufacturing Technology in Turbine Blade and Vane Gas Turbine Experiment and Research 29 (6) 2016: pp. 44-55. https://doi.org/10.3969/j.issn.1672-2620.2016.06.010

7. Hu, B., Hu, F.Y., Guan, R.G., Huang, X.R. Crystal Orientation and Performance of Laser Directional Cladding on DZ22 The Chinese Journal of Nonferrous Metals 23 (7) 2013: pp. 1969-1976.

8. Lu, H.Y., Li, S.M., Zhong, H., Fu, H.Z. $\quad$ Orientation Growth of Peritectic Phase in Directionally Solidified NdFeB Permanent Magnet Alloys Chinese Journal of $R$ are Metals 39 (2) 2015: pp. 111-117. https://doi.org/10.13373/j.cnki.cjrm.2015.02.003

9. Xue, Y.L., $\quad$ Li, S.M., $\quad$ Li, K.W., Zhang, T., Fu, H.Z. Microstructure Evolution and Preferred Growth Direction of Laves Phase $\mathrm{Cr}_{2} \mathrm{Nb}-20 \mathrm{Ti}$ Alloy During Directional
Solidification Rare Metalmaterials and Engineering 44 (2) 2015: pp. 375-380

10. Chen, T.J., Li, X.W., Guo, H.Y., Hao, Y. Microstructure and Crystal Growth Direction of Al-Cu Alloy Transactions of Nonferrous Metals Society of China 25 2015: pp. 1399-1409. https://doi.org/10.1016/S1003-6326(15)63739-6

11. Boettinger, W.J., The Structure of Directionally Solidified Twophase $\mathrm{Sn}_{2} \mathrm{Cd}$ Peritectic Alloys Metallurical Transactions 5 1984: pp. 2023-2031. https://doi.org/10.1007/BF02644495

12. Walton, D., Chalmfers, B., The Origin of the Preferred Orientation in the Columnar Zone of Ingots Transactions of the Metallurgical Society of the American Institute of Mining, Metallurgical and Petroleum Engineers 1999: pp. $447-456$

13. Lee, J.H., Verhoeven, J.D. Peritectic Formation in the $\mathrm{Ni}_{2} \mathrm{Al}$ System Crystal Growth 144 1994: pp. 353-366. https://doi.org/10.1016/0022-0248(94)90477-4

14. Liu, Y.C., Yang, G.C., Guo, X.F. Coupled Growthed Behavior in Rapidly Solidified Ti-Al Peritectic Alloys Crystal Growth 222 2001: pp. 645-654. https://doi.org/10.1016/S0022-0248(00)00946-5

15. Meng, W. Directional Solidification Structure and Phase Selection of $\mathrm{Zn}-\mathrm{Cu}$ Coated Alloy Northwestern University of Technology XiAn 2002: pp. 74-76.

16. Cui, W.F. The Law of Oxygen Diffusion in Ti-1100 Superalloy Oxidation Journal of Northeastern University 1 1998: pp. 19-22.

17. Qi, K.F., Yang, M., Li, S.H. Microstructure and oxidation behavior of Ti(C,N)-based cermets with in situ synthesized $\mathrm{Ni} 3 \mathrm{Al}$ phase International Journal of Refractory Metals and Hard Materials 73 2018: pp. $157-161$. https://doi.org/10.1016/j.ijrmhm.2018.02.008

18. Wang, M.Q., Qu, J.L., Yin, T.Z. Study on High Temperature Oxidation Behavior of GH4720Li Alloy Journal of Iron and Steel Research 22 (9) 2010: pp. $28-33$. https://doi.org/10.1155/2010/293410 